\title{
O CAMPANIFORME CORDADO DE FORNO DOS MOUROS (TOQUES, A CORUÑA) ${ }^{1}$
}

\section{THE CORDED BELL BEAKER OF FORNO DOS MOUROS (TOQUES, A CORUÑA)}

\author{
M ${ }^{a}$ PILAR PRIETO MARTÍNEZ ${ }^{2}$, ÓSCAR LANTES SUÁREZ ${ }^{3}$ \\ $\&$ ANTONIO MARTÍNEZ CORTIZAS ${ }^{4}$
}

\begin{abstract}
Resumen
En este artículo se da a conocer el vaso campaniforme cordado del dolmen de Forno dos Mouros (Toques, A Coruña) como una pieza excepcional en el contexto regional. Se aportan novedades sobre las técnicas decorativas empleadas e información arqueométrica que nos permite conocer otros aspectos del recipiente hasta ahora inéditos. Destaca su fabricación cuidada, elaborada y local pero con influencias decorativas vinculadas íntimamente con la Bretaña francesa, consecuencia de las complejas redes de circulación existentes en III milenio BC en Europa.
\end{abstract}

\section{Palabras clave}

Cerámica campaniforme, CZ/M, Impresión de concha y cuerda, Análisis arqueométricos, Galicia.

\begin{abstract}
In this paper we present the corded zone maritime bell beaker of Forno dos Mouros Dolmen (Toques, A Coruña), an exceptional piece in the regional context. New features of the decorative techniques used and archaeometric determinations (i.e. mineralogical and geochemical composition) allowed to know other aspects of this vase, until now unpublished. The results emphasize a local manufacture but with strong decorative influences linked to Britanny (France), consequence of the complex networks of circulation in III millenium BC in Europe.
\end{abstract}

\section{Key words}

Bell Beaker pottery, CZ/M, Shell and corded impression, Archaeometric analyses, Galicia.

1 Este artigo foi entregado á esta revista o 10 de agosto de 2007.

${ }^{2}$ Laboratorio de Paleoambente, Patrimonio e Paisaxe (IIT- Universidade de Santiago de Compostela), Unidade Asociada IEGPS (CSIC-Xunta de Galicia)-USC.

${ }^{3}$ Unidade de Arqueometría. RIAIDT, Universidade de Santiago de Compostela.

${ }^{4}$ Departamento de Edafoloxía e Química Agrícola, Facultade de Bioloxía, Universidade de Santiago de Compostela. 


\section{INTRODUCCIÓN}

O Dolmen de Forno dos Mouros foi sondeado en 1984 e escavado máis tarde en 1989 (Criado \& Vaquero 1991), dentro do marco do proxecto Bocelo Furelos, baixo a dirección de Felipe Criado (Criado et alii 1991). Este xacemento é importante, entre outros motivos, porque nel atopouse o primeiro recipiente de campaniforme CZ/M (Corded Zone/Maritime) coñecido e ben contextualizado en Galicia.

Así, o obxectivo deste traballo é dar a coñecer este recipiente, que xa foi obxecto de estudios preliminares en traballos anteriores (Prieto 1999a, 1999b). Neste senso, este traballo é novedoso, non só pola propia excepcionalidade do recipiente e pola súa escasez numérica en Galicia respecto a Europa, senón porque aportamos novidades en canto ás súas técnicas decorativas, así como información arqueométrica, que nos permiten dilucidar outros aspectos até agora inéditos.

Este campaniforme forma parte do escaso número de recipientes con decoración cordada en Galicia, facendo un total de cinco (figura 1a).

Por unha banda, amáis do vaso do dolme de Forno dos Mouros, atopouse un pequeno fragmento de CZ/M no xacemento de Budiño, que foi recuperado no marco da excavación do xacemento paleolítico, dirixida por Dolores Cerqueiro a principios dos anos noventa do século pasado (Cerqueiro 1996). Este fragmento está integrado nun conxunto de 182 fragmentos de cerámica da Idade do Bronce Inicial (uns 44 recipientes), dos cales a metade presentan decoración campaniforme (Prieto 1999a). Por outra banda, destacan outros tres xacementos galegos xa publicados, nos que se rexistrou campaniforme tipo AOC (All Over Corded), o recentemente publicado de Monte dos Marxós (Suárez e Lestón 2005), o de Abrigo de Arca dos Penedos (Eguileta, Fernández e Seara 1993-4) e o de A Fontenla (Peña 1985); ó que habería que engadir, pola súa proximidade xeográfica, o de Castelo Velho no Norte de Portugal (S.O. Jorge 2002).

Polo tanto, vemos que o contexto destes recipientes é variado, documentándose tanto en abrigos, como en asentamentos ó ar libre, como en contextos funerarios tumulares; se ben, os mellores documentados son estes últimos. Asimesmo obsérvase unha ampla distribución, tanto no interior como na costa. 


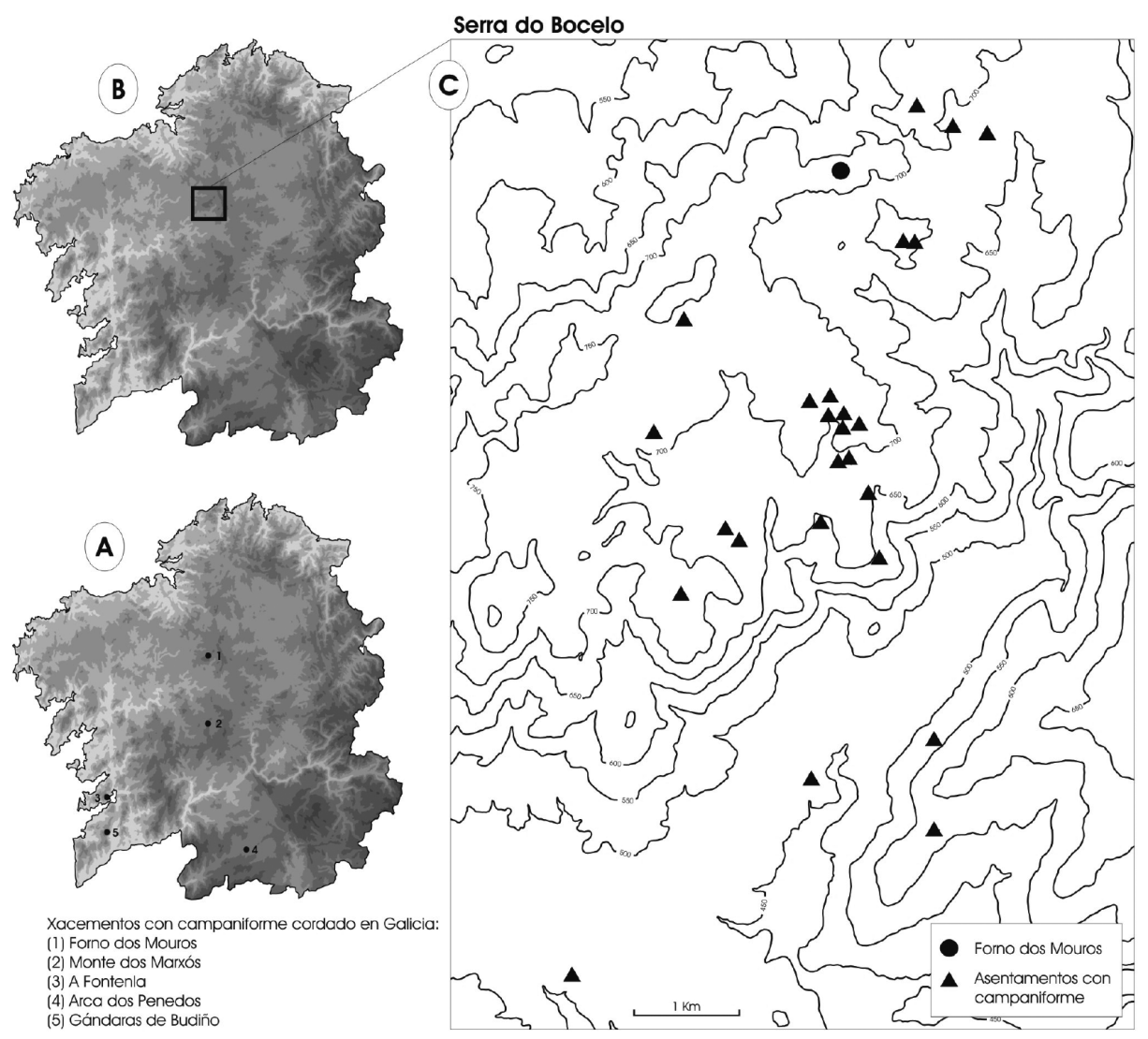

Figura 1: Mapa de localización dos xacementos con cerámica cordada en Galicia (a), do Dolmen de Forno dos Mouros (b) e (c) detalle do entorno arqueológico.

\section{O XACEMENTO}

O Dolmen de Forno dos Mouros localízase na Serra do Bocelo a 713 m.s.n.m., no lugar de Moruxosa, parroquia de Paradela, Concello de Toques, provincia de A Coruña (coordenadas UTM-X: 583536, UTM-Y: 4762853). Ubícase sobre un relevo plano terminal da serra, cumio dunha suave prominencia que domina a liña divisoria de augas con pendente nula. Xeolóxicamente presenta substrato de ortogneis con afloracións nas inmediacións. A uns $200 \mathrm{~m}$ cara ó S discorre un pequeño regato que desauga na cabeceira do río Abelá. A 20 m cara ó N e ó outro lado do Camiño Real, localízase outro pequeno túmulo (Criado \& Vaquero 1991). Nun contorno duns $10 \mathrm{~km}$, e sobre todo cara a metade $\mathrm{S}$, localízanse unha vintena de xacementos con ocupacións campaniformes (Méndez 1998) (figura 1b e 1c). 
O dolme de Forno dos Mouros presenta unha cámara con restos de pintura no interior, un corredor de acceso de dous tramos e dous aneis perimetrais superpostos, recubertos por un túmulo complexo. A lousa de cuberta foi fracturada na súa parte septentrional faltándolle aquí un considerable fragmento. Desgraciadamente, non se dispoñen de datacións radiocarbónicas para este xacemento. As diferentes fases constructivas do monumento serían as seguintes:

- Unha primeira fase na que se constrúe a cámara, o corredor e o primeiro anel.

- Un segundo momento no que se documenta unha acumulación de pedras que cega o corredor por unha fina banda de pequenas pedras.

- Un terceiro momento, no que se engade un segundo anel perimetral conformado por pedras de un granito distinto que, no seu contacto coa salida do corredor, deixou un semicírculo coincidente cun burato de entrada, semellando un segundo acceso a cámara selado por un conxunto de pedras miúdas.

No corredor, e sen deixar restos de estructuras evidentes, depositouse un recipiente campaniforme cordado $\mathrm{CZ} / \mathrm{M}$, fragmentado in situ, do que se conservan unha vintena de pezas que permiten reconstruir tres cuartas partes do perfil do recipiente. Esta deposición responde a unha reutilización do dolme, e probablemente sexa unha deposición única.

Finalmente, recuperáronse no xacemento uns 200 fragmentos de cerámica moi fragmentada, feita a torno, de época moderna, consecuencia de violacións posteriores.

\section{CARACTERÍSTICAS DO VASO CORDADO}

$\mathrm{O}$ vaso presenta un perfil en $\mathrm{S}$ suave (figura 2). Aínda que non se conserva o borde, apréciase a súa orientación aberta continuando cun colo estrangulado, cóncavo e esbelto, unha panza convexa baixa e fondo redondeado convexo. O diámetro da boca ronda os $220 \mathrm{~mm}$, o colo $210 \mathrm{~mm}$, e a zona de máxima expansión da panza $230 \mathrm{~mm}$, cunha altura aproximada de 190-200 mm. É un recipiente de gran tamaño, que ronda os 6 litros de capacidade.

No que se refire á manufactura, é un recipiente feito a man. Un exame en lupa binocular da súa fractura fresca, xunto á ausencia das marcas horizontais típicas dos churros permíteunos precisar que a técnica de modelado é por presión. $\mathrm{O}$ acabado superficial exterior é o alisado fino, mentres que o interior non se conserva, xa que aparece descunchado de modo moi regular por toda a súa superficie. A cor superficial é un vermello ladrillo de aspecto brilante, que se mantén igualmente en fractura, polo cal, non responde ás fracturas en sándwich tan frecuentes nos vasos cam- 

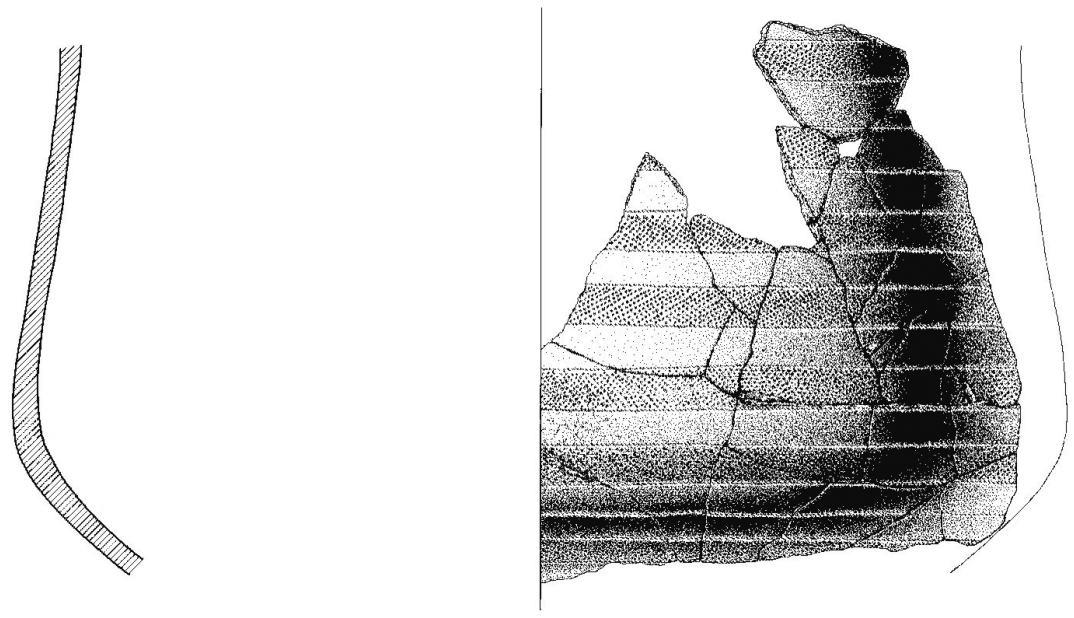

$5 \mathrm{~cm}$

Figura 2: Debuxo arqueolóxico do campaniforme de Forno dos Mouros.

paniformes galegos. A textura é compacta e fina, e o desgrasante é invisible nun exame macroscópico, en lupa apréciase que a granulometría media oscila entre 0,3 a 0,1 mm (Figura 3c). Cabe destacar asimesmo, a regularidade das paredes ó longo do perfil do recipiente, que non supera os $6 \mathrm{~mm}$ de grosor, e que está en relación ca apariencia coidada xeral do recipiente nas fases de manufactura exceptuando o acabado interior. En termos de fabricación, pódese afirmar que se invertíu un gran esforzo para elaborar coidadosamente este recipiente, a pesares de non posuír unha alta calidade para funcións cotiás debido á súa aparente baixa impermeabilidade e pouco grosor. As análises arqueométricas efectuadas á peza aportaránnos máis información neste senso como veremos máis adiante.

En relación coa decoración, temos un esquema decorativo simétrico e cubrinte, que deixa libre de decoración a área inmediata ó borde e á zona de apoio da base. Está conformado por 3 elementos decorativos e xeométricos rectilíneos: liñas horizontais que delimitan liñas oblicuas, estas últimas poden estar orientadas á esquerda ou á dereita. Así, o motivo articúlase con dous elementos, a liña horizontal como acotadora dunha das variantes oblicuas, de modo alternante. A anchura das bandas decoradas e non decoradas son semellantes, contribuíndo ambas a dar un efecto de equilibrio visual ó conxunto do vaso. No que se refire ás técnicas, rexístrase a impresión de dous instrumentos diferentes, por un lado, de corda de un fío en S, aplicada de modo moi fino e coidado, e por outro lado, impresión de cuncha, probablemente dunha cuncha que L. Salanova identificóu por primeira vez (1992a) como coquille 
fine, da que non poido afinar a especie, bastante próxima ás improntas de ameixa dentada (Donax vittatus). Isto último é unha novidade importante, xa que as investigacións anteriores (Prieto 1999a) describíano coma un puntillado moi coidado (figura 3d). Así que nos atopamos ante un caso único, polo momento, no que se refire a decoración de cuncha. Ata o momento, en Galicia, o único caso de impresión de cuncha en contexto funerario localizábase nun recipiente de Mina da Parxubeira, decorado con zamburiña (Chlamis opercularis) (Rodríguez 1988). Decoración, por outra banda, moi frecuente nas decoracións campaniformes de contextos domésticos, especialmente nos hábitats máis alonxados da costa galega, sendo os xacementos de $\mathrm{A}$ Lagoa (Méndez 1994), os que mostran unha maior variabilidade en canto a improntas (tamaños, morfoloxías das improntas e profundidades) (Prieto 1999a e 1999b).

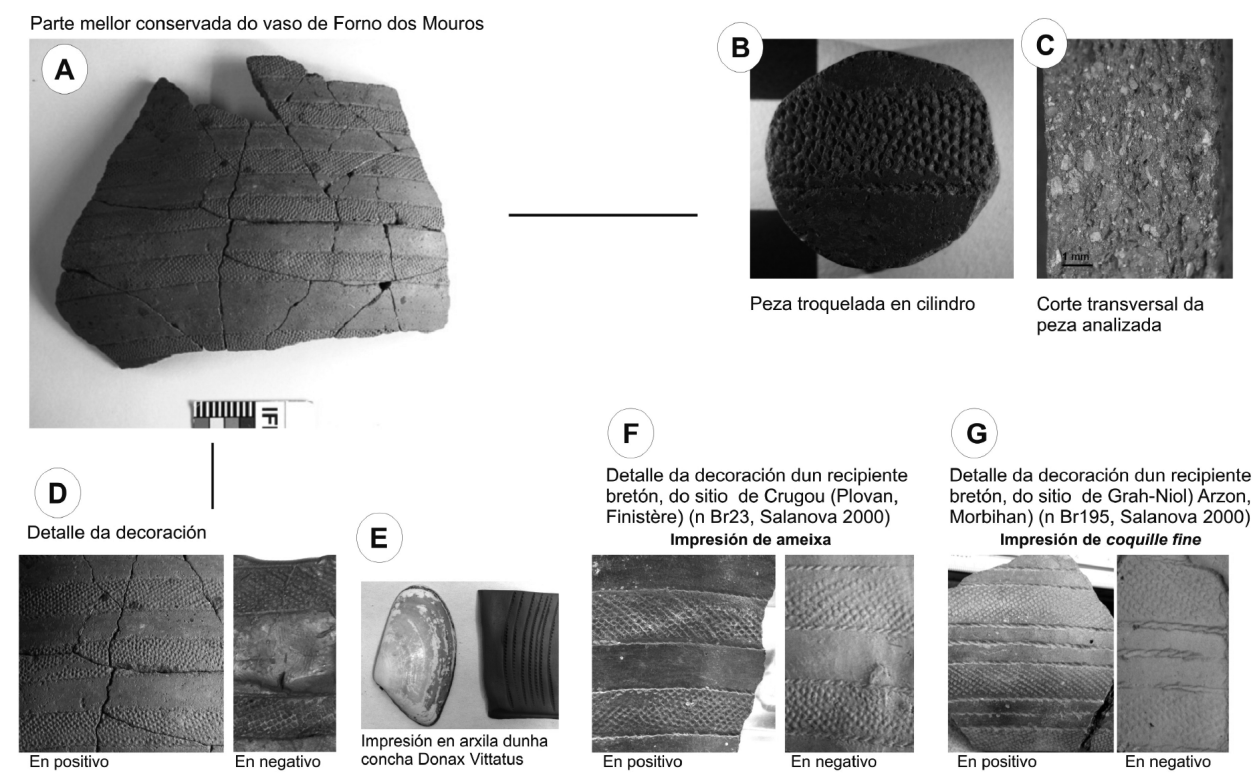

Figura 3: Fotografías do campaniforme de Forno dos Mouros e dous campaniformes bretóns.

\section{RELACIÓNS DE CONTEXTO}

Os rasgos deste recipiente, nun nivel morfolóxico, técnico e decorativo, correspóndense cos típicos do campaniforme estándar, ben definido por Salanova (1997, 2000). Sen embargo, atopámonos con certas 'anomalías' formais, que pasamos a tratar seguidamente. 
A primeira rareza deste recipiente é a técnica de modelado, xa que non é frecuente atopar campaniformes feitos ca técnica a presión, sendo habitual o emprego de churros. A elo súmase o gran tamaño do vaso, con 6 litros de capacidade. Se revisamos os tamaños dos recipientes funerarios campaniformes que se poden reconstruir dentro da área galega, vemos que os vasos de Vilavella oscilan entre 1,1 e 1,6 litros, os de Parxubeira 2, entre 1,4 e 2 litros, os de Tecedeiras entre 0,7 e 1 litro, os de San Cosme, entre 1 e 3 litros e a cazola de Roupar alcanza 4,4 litros. O vaso campaniforme de Forno dos Mouros convírtese así no de maior volume documentado en contextos funerarios galegos. Os vasos cordados que se poden reconstruir, como son os de Monte dos Marxós e Arca dos Penedos, con 2 litros e 1,8 litros aproximadamente (figura 4), entran no patrón dos anteriormente citados, polo que vemos como destaca polo seu tamaño o de Forno dos Mouros. E se tomamos como exemplo a Bretaña francesa, máis alonxada pero cunha porcentaxe elevadísima de campaniforme estándar en contextos funerarios -básicamente-, vemos que os volumes dos recipientes campaniformes raramente exceden os 2,5 litros, sendo excepcionais os que oscilan entre 5 e 11 litros de capacidade. Existe como vemos, unha certa norma en canto ó tamaño dos recipientes campaniformes Galegos e Bretóns de contextos funerarios. Neste aspecto, o campaniforme de Forno dos Mouros presenta unhas características morfolóxicas atípicas, que poderían estar relacionadas quizáis co estatus do defunto, pero que en todo caso se nos escapan.

Finalmente, atopámonos cunha excepción no campo das técnicas decorativas, que se relaciona no só ca propia escasez de recipientes con decoración cordada en Galicia, senón e sobre todo, coa presenza de impresión de cuncha, un tipo de cun-
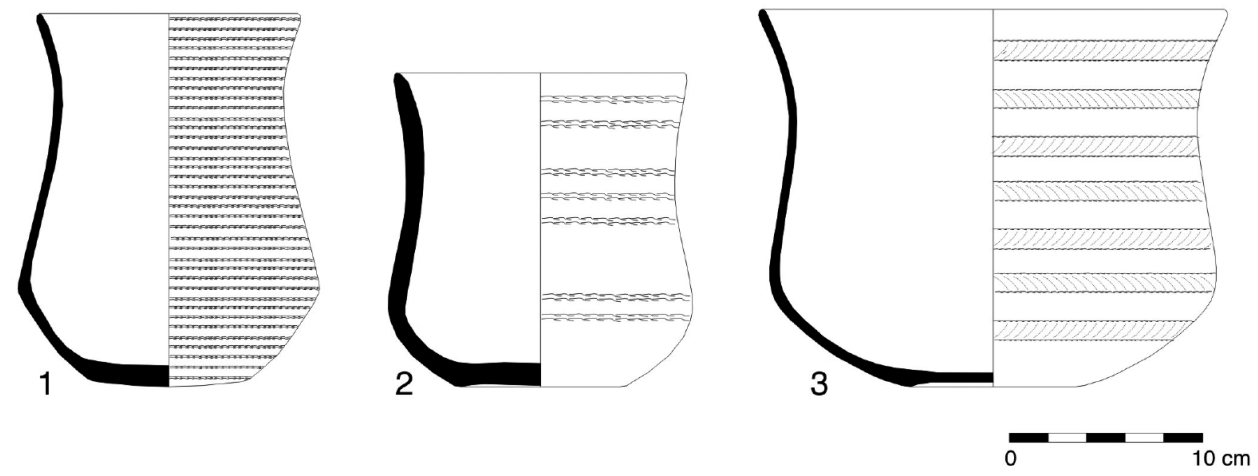

Figura 4: Reconstruccións dos campaniformes de (1) Monte dos Marxós, de (2) Arca dos Penedos (según Suárez e Lestón 2005) e de (3) Forno dos Mouros. 
cha descoñecido para o campaniforme galego como útil para decorar. Trátase da ameixa dentada (Donax vittatus) aplicada con suavidade sobre a superficie ou dunha cuncha fina ou coquille fine sin identificar polo momento, que se distribúe xeográficamente pola costa atlántica, desde o $\mathrm{N}$ de Europa ata o $\mathrm{N}$ de África, e que actualmente en Galicia está esquilmada, aínda que nas costas bretonas segue sendo abundante.

Precisamente, os campaniformes bretóns de estilo marítimo presentan a orixinalidade de estar decorados con estes tipos de cuncha (figuras $3 \mathrm{e}, 3 \mathrm{f}$ e $3 \mathrm{~g}$ ) e tamén con berberecho (Salanova 1992b). Sen embargo, a identificación do tipo de instrumento utilizado presenta dificultades, e en ocasións é difícil diferenciar a impresión de peine e a de cuncha nas súas variedades de coquille fine, ameixa (Donax vittatus) e berberecho (Cerastoderma edule) (Salanova 1992a). Salanova (2000) revisou as áreas campaniformes nas que se utiliza a impresión de cuncha como técnica decorativa, e atopou que son xacementos de áreas costeiras os que albergan unha maior cantidade de recipientes con esta decoración, predominando as atlánticas. As dúas zonas privilexiadas son Bretaña e Portugal, sendo máis puntual en Gran Bretaña (Clarke 1970), Dinamarca (Jensen 1973) e Galicia (Rodríguez Casal 1988). No Mediterráneo, o Languedoc-Roussillon é a área máis destacada, aínda que non posúe un número tan grande coma as anteriormente citadas, e só puntualmente na costa española (Harrison 1977) ou francesa, e no N de Italia (Barfield 1974) documéntanse campaniformes con decoración de cuncha. Sen embargo, en todas estas zonas documéntase o cardium como instrumento salvo en Galicia onde se emprega a zamburiña.

$\mathrm{Na}$ actualidade, ampliáronse as áreas campaniformes nas que se recoñece o uso das cuncha para decorar (figura 5). Dinamarca, por exemplo, ofrece un número maior de xacementos con campaniforme decorado con berberecho, alomenos 10 (asentamentos como Thy2453/2757, Thy2758, Myrhøj, Lodbjerg Sandhills, Diverhøj e Tastum, Bejsebakken ou enterramentos como Blaere e Borup Riis). ${ }^{7}$ En Galicia, case o $20 \%$ dos campaniformes (sobre 550 vasos) posúen decoración de impresión de cuncha de zamburiña, e sobre todo proceden de asentamentos do interior e maioritariamente correspóndense con variedades rexionais e non estándares. Sen embargo, estas porcentaxes quedan lonxe das atopadas en Bretaña, en torno ó 54\% dos campaniformes bretóns teñen decoración de impresión de cuncha, berberecho e ameixa, e un tipo sen determinar todavía, e ó contrario que Galicia, son campaniformes estándar e de contextos funerarios costeiros.

5 Unha síntese sobre o campaniforme danés preparada por P. Prieto (2008) está actualmente en revisión na N. A. R. 


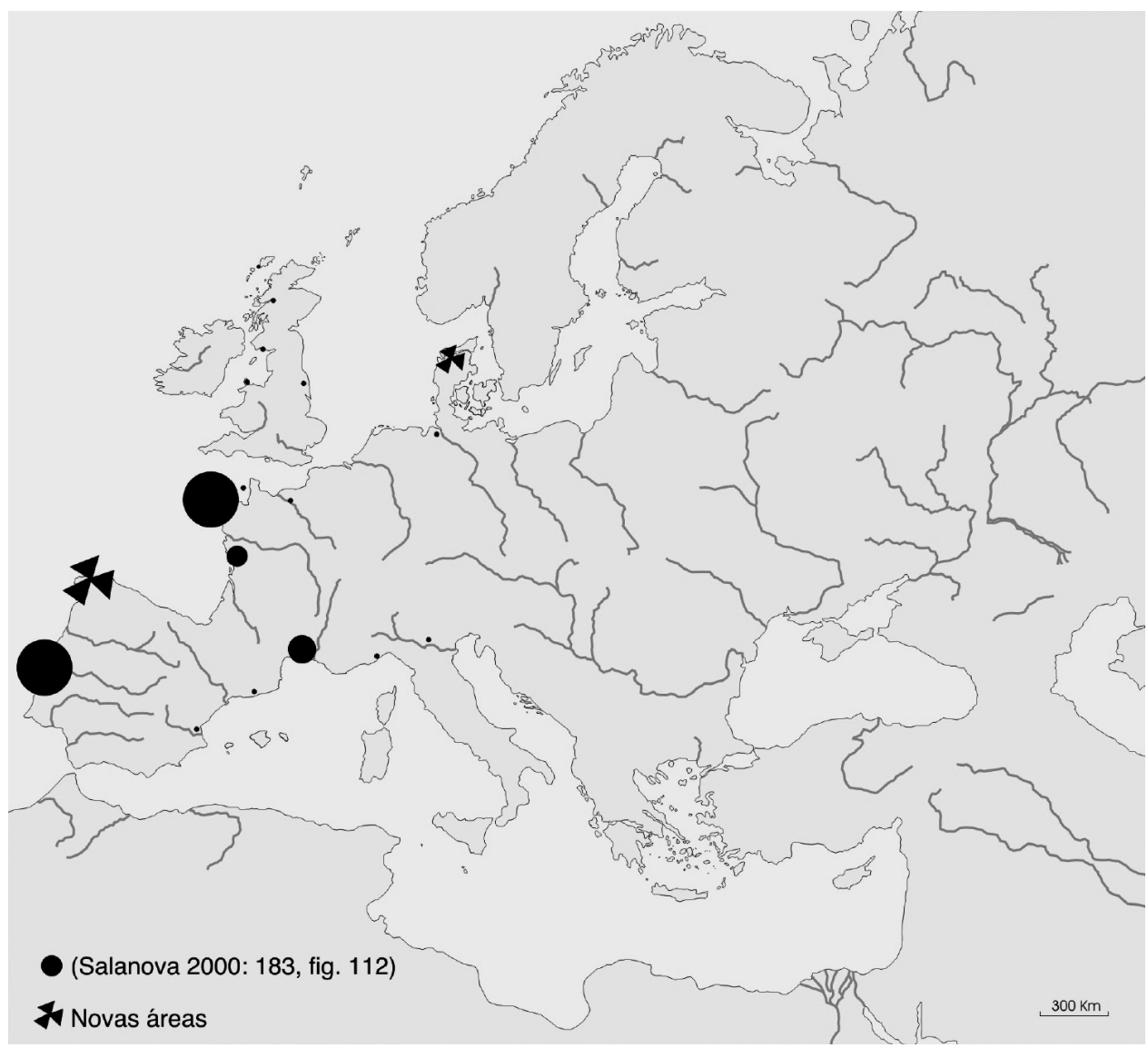

Figura 5: Áreas de distribución de campaniforme en Europa onde se documentan decoración feitas con impresión de cuncha.

É chamativo que, precisamente, sexa un CZ/M de contexto funerario, que responde ó modelo estándar de campaniforme, o que posúe decoración de cuncha de coquille fine ou ameixa. Se revisamos os xacementos coñecidos en Galicia, obsérvase unha norma ben establecida, que é que tódolos recipientes campaniformes dos enterramentos mostran un patrón plenamente estandarizado, mentres que só da orde dun $30 \%$ dos asentamentos publicados presentan campaniformes con estas mesmas características (figura 6). O resto dos asentamentos albergan recipientes que se poden considerar coma variantes rexionais acompañados de maneira excepcional por vasos estándar (Prieto 2007).

Polo tanto, tendo en conta a utilización dun tipo de cuncha descoñecido como instrumento para decorar os vasos campaniformes en contextos galegos, non é des- 
cartable pensar que este recipiente sexa o resultado de mecanismos de circulación entre Bretaña e Portugal, donde Galicia sen dúbida ocupa un lugar xeográfico privilexiado. Sen embargo diversos aspectos coma o tamaño do recipiente, a técnica de modelado e o carácter local da pasta (análise da arxila e desgrasante que veremos máis adiante) coa que foi elaborado o cacharro inclina a pensar que non é o recipiente o que viaxa senón o modelo, falando entón dunha circulación de ideas, unha comunicación de técnicas e incluso de instrumentos, xa que a cuncha ten que vir da costa (a máis cercana do Bocelo está ó $\mathrm{N}$ a uns $50 \mathrm{~km}$ ).

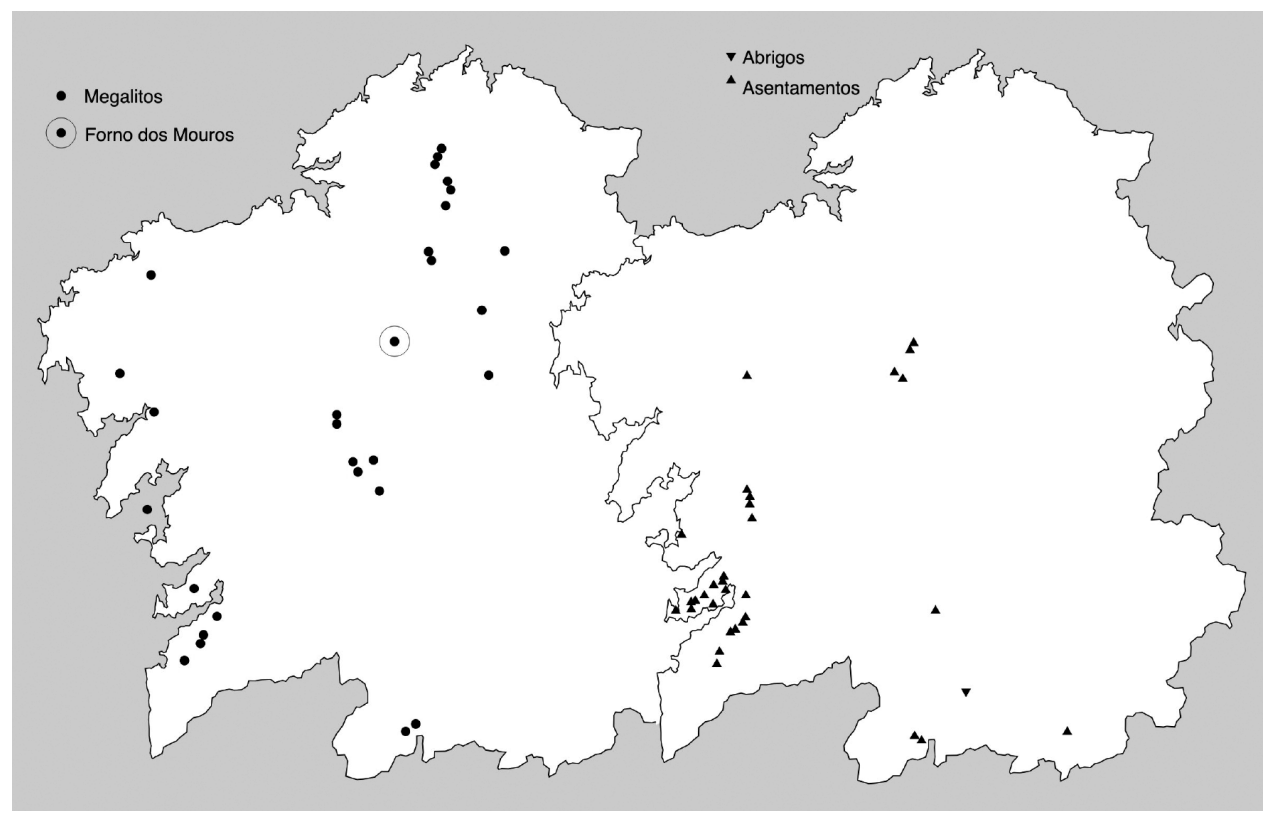

Figura 6: Distribución de xacementos en Galicia onde predominan os campaniformes estándar ou marítimos.

\section{ANÁLISES ARQUEOMÉTRICAS}

Se ben en Galicia a alfarería é o tema mellor coñecido actualmente para o periodo cultural de que estamos a falar, a orientación arqueométrica é todavía unha aportación anecdótica (Guitián e Vázquez 1981; Andrés, Menéndez y Muñoz 1993; Prieto 1993; Taboada, Carreño e Guitián 1994; Rey e Soto 2002; Prieto, Juan e Matamala 2005). Para un estudio cerámico completo é sempre necesario analizar un número significativo de pezas no tempo e no espacio. Sen embargo, a análise desta peza ailla- 
da, polas súas particularidades anteriormente expostas, permítenos relacionala con aspectos máis amplos dentro do fenómeno campaniforme; xa que podemos extraer información da súa tecnoloxía de fabricación e da orixe local ou non da arxila e desgrasantes cos que foi confeccionada. Con ese obxectivo someteuse a determinacións arqueométricas o singular fragmento campaniforme de Forno dos Mouros.

Esta significativa peza foi analizada textural, mineralóxica e xeoquímicamente. A metodoloxía utilizada descríbese en Martínez, Lantes e Prieto (2008) e consiste básicamente na descripción das dimensións e color, toma de fotografía, pulido para o estudio dun corte transversal, determinación da composición xeoquímica (concentración de elementos químicos mayoritarios, minoritarios e traza) das caras externa e interna, posterior moenda ata un tamaño de grao de $50 \mu$, homoxenización e determinación de composición xeoquímica e mineralóxica no pó. Esta secuencia de análisis permítenos obter unha alta cantidade de información a partir dun mesmo fragmento, o que optimiza a análise arqueométrica e minimiza a cantidade de mostra requerida.

O fragmento orixinal é unha peza de cor roxiza externa e interna de $26,81 \mathrm{~mm}$ de alto por 28,35 $\mathrm{mm}$ de ancho, sendo o grosor medio de 4,89 $\mathrm{mm}$. Na figura $3 \mathrm{~b}$ apréciase a peza troquelada en cilindro (unha das fases da preparación da mostra) na que se aprecia a cor e a perfección dos motivos decorativos impresos.

A textura do fragmento é de grao fino de redondeado a subredondeado e homoxeneamente distribuído pola peza (Figura 3c). Á lupa, como desgrasante identifícase cuarzo (cor leitoso-grisáceo) e aparentemente plaxioclasa ou feldespato (cor branca amarelenta mate), sen embargo a posterior análise mineralóxica confirmaranos que se trata exclusivamente de cuarzo. A matriz é fina, de cor roxiza a alaranxada intensa e homoxénea (non se observan fenómenos de sandwich nen cambios cromáticos).

\section{RESULTADOS ANALÍTICOS E INTERPRETACIÓN MINERALÓXICO- XEOQUÍMICA}

A análise de difracción de raios X (figura 7) desvela que o único mineral desgrasante identificado é cuarzo, a pesares de sospeitar a presenza de plaxioclasa no exame textural. Tamén se detecta en baixas proporcións hematita (responsable da intensa cor roxiza da matriz arxilosa) e haloisita. A ausencia de caolinita, mineral secundario moi abundante nas arxilas dos productos de meteorización, indícanos que a temperatura de cocción foi superior ós $550^{\circ} \mathrm{C}$, temperatura á que este mineral perde a súa cristalinidade e se volta "invisible" á difracción de raios X. De feito, a haloisita detectada podería terse formado por reorganización dos productos de destrucción térmica da caolinita, en equilibrio físico-químico co solo no que estivo enterrada a peza. 


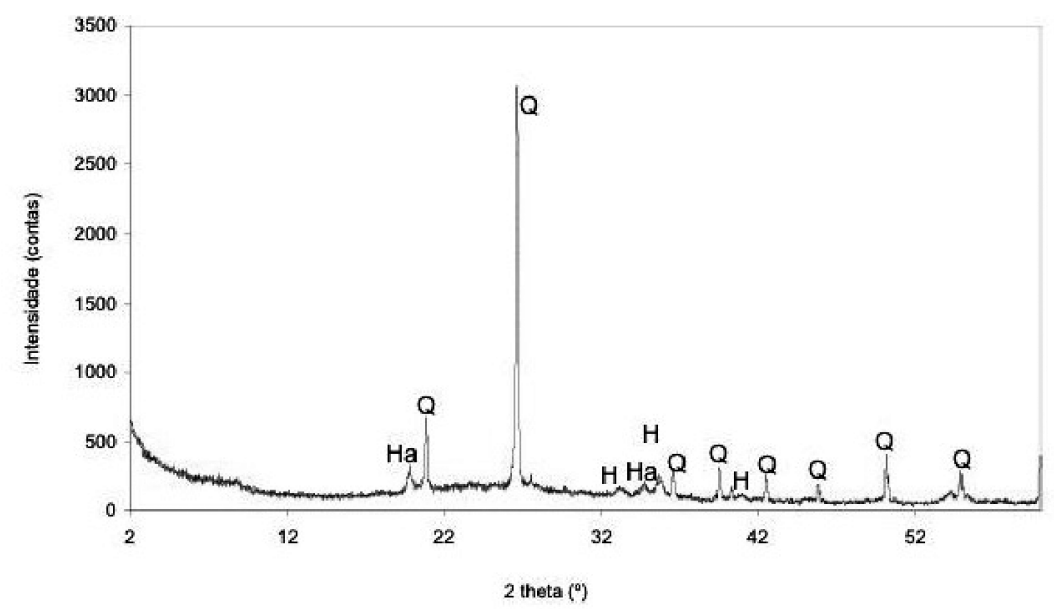

Figura 7: Difractograma de raios $\mathrm{X}$ de po cristalino do fragmento campaniforme.

A análise xeoquímica é un paso máis na caracterización do fragmento. Apórtanos a información elemental. Neste proceso metodolóxico sempre se procede analizando previamente o interior e o exterior da peza co gallo de detectar cambios debidos a acabados externos, decoracións, uso da cerámica, postdeposicións, migracións de elementos, etc. Posteriormente analízase a peza enteira homoxenizada en forma de pó. Son dúas as variantes das técnicas utilizadas, fluorescencia de raios $\mathrm{X}$ de elementos lixeiros e de elementos traza. Os espectros obtidos para lixeiros e traza en peza total amósase nas figuras 8 e 9 onde se indican os elementos químicos detectados e cuantificados. O conxunto de datos xeoquímicos preséntanse na táboa 1. Centrándonos nas concentracións da peza completa, podemos apreciar como o silicio $(20,2 \%)$, o ferro $(14,2 \%)$ e o aluminio $(9,8 \%)$ son os elementos maioritarios. O silicio está contido no cuarzo e na matriz arxilosa -non identificada en difracción de raios X por estar en estado amorfo- como aluminosilicatos. $\mathrm{O}$ aluminio tamén ten a súa orixe nas arxilas. O ferro identifícase coma hematita, sen embargo a alta porcentaxe detectada na análise elemental indícanos que unha alta proporción debe atoparse en estado amorfo (oxi-hidróxidos non-cristalinos ou de baixa cristalinidade), iso sí, contribuíndo á cor da peza. O contido de potasio (2,7 \%) é característico de minerais e productos de degradación de materiais graníticos alcalinos, así como o baixo contido en calcio $(0,18 \%)$. A alta concentración de titanio $(1,2 \%)$ é semellante á de arxilas formadas a partir de materiais graníticos (Taboada et alii 2006).

Do resto de elementos químicos determinados, tan só oito superan os $100 \mu \mathrm{g} \mathrm{g}^{-1}$ (Mn, P, Cr, Zr, Rb, Ni, S e Zn) (táboa 1). O resto, a excepción do Br, atópanse en 
concentracións inferiores a $50 \mu \mathrm{g} \mathrm{g}^{-1}$. É tamén destacable a presencia de elementos caracterísiticos da materia orgánica, como $\mathrm{C}$ e $\mathrm{N}$, en concentracións detectables. A relación $\mathrm{C} / \mathrm{N}$ é de moderada a alta $(17,2)$.

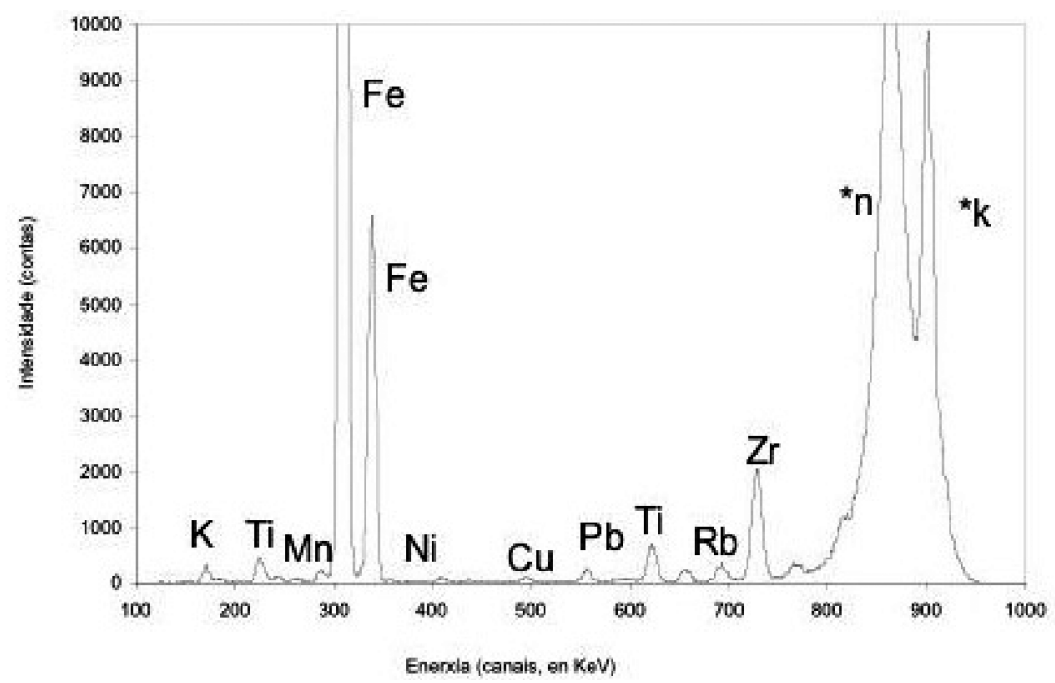

Figura 8: Espectro de fluorescencia de raios $\mathrm{X}$ de elementos traza (mostra total) do fragmento campaniforme.

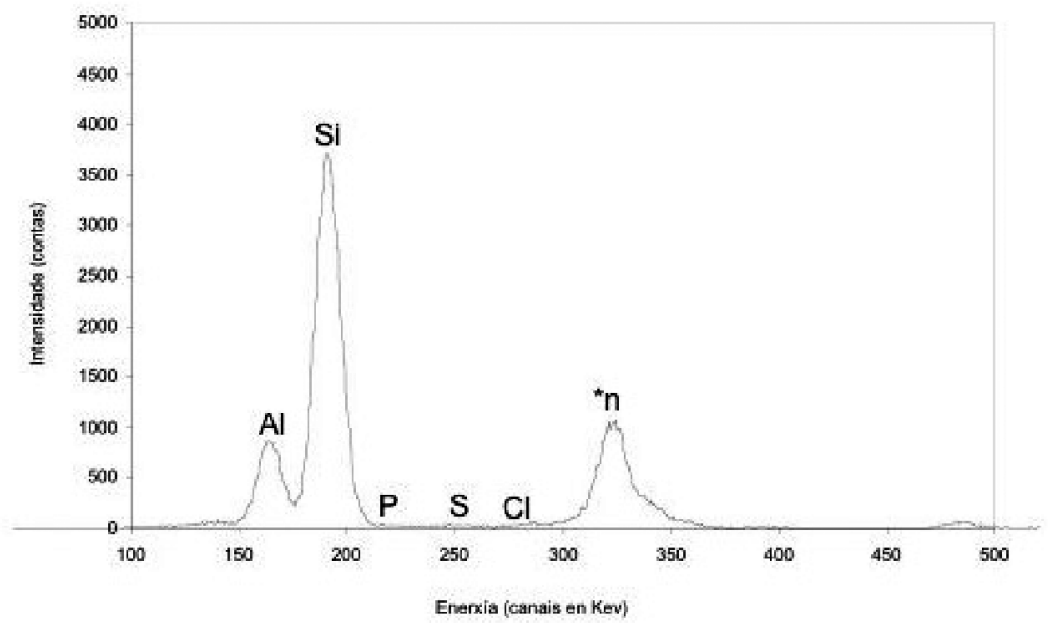

Figura 9: Espectro de fluorescencia de raios X de elementos lixeiros (mostra total) do fragmento campaniforme. 


\begin{tabular}{|c|c|c|c|c|c|}
\hline & Exterior & Peza completa & Interior & $\mathrm{E} / \mathrm{T}$ & $\mathrm{I} / \mathrm{T}$ \\
\hline \multicolumn{6}{|c|}{ Elementos Maioritarios (en \%) } \\
\hline $\mathrm{Mg}$ & $<$ I. d. & $<$ I. d. & $<$ I. d. & - & - \\
\hline $\mathrm{Al}$ & 6,44 & 9,76 & 8,12 & 0,7 & 0,8 \\
\hline S.i & 13,84 & 20,20 & 15,84 & 0,7 & 0,8 \\
\hline K & 2,41 & 2,68 & 2,22 & 0,9 & 0,8 \\
\hline $\mathrm{Ca}$ & 0,15 & 0,18 & 0,18 & 0,8 & 1,0 \\
\hline $\mathrm{Ti}$ & 1,07 & 1,20 & 1,11 & 0,9 & 0,9 \\
\hline $\mathrm{Fe}$ & 12,66 & 14,19 & 12,70 & 0,9 & 0,9 \\
\hline $\mathrm{C}$ & - & 1,89 & - & - & - \\
\hline $\mathrm{N}$ & - & 0,11 & - & - & - \\
\hline \multicolumn{6}{|c|}{ Elementos minoritarios e traza (en ppm. mg./Kg.) } \\
\hline $\mathrm{P}$ & 292 & 508 & 515 & 0,6 & 1,0 \\
\hline S & 492 & 105 & 50 & 4,7 & 5,2 \\
\hline $\mathrm{Cl}$ & $<$ I. d. & $<$ I. d. & 369 & - & - \\
\hline $\mathrm{Cr}$ & 339 & 372 & 273 & 0,9 & 0,7 \\
\hline $\mathrm{Mn}$ & 2818 & 843 & 611 & 3,3 & 0,7 \\
\hline $\mathrm{Ni}$ & 100 & 108 & 93 & 0,9 & 0,9 \\
\hline $\mathrm{Cu}$ & 29 & 29 & 31 & 1,0 & 1,1 \\
\hline $\mathrm{Zn}$ & 104 & 103 & 97 & 1,0 & 0,9 \\
\hline $\mathrm{Ga}$ & 26 & 30 & 32 & 0,9 & 1,1 \\
\hline As & 27 & 29 & 28 & 0,9 & 1,0 \\
\hline $\mathrm{Br}$ & 82 & 81 & 90 & 1,0 & 1,1 \\
\hline $\mathrm{Rb}$ & 135 & 135 & 129 & 1,0 & 1,0 \\
\hline $\mathrm{Sr}$ & 39 & 41 & 38 & 1,0 & 0,9 \\
\hline $\mathrm{Y}$ & 32 & 48 & 31 & 0,7 & 0,7 \\
\hline $\mathrm{Zr}$ & 200 & 245 & 246 & 0,8 & 1,0 \\
\hline $\mathrm{Nb}$ & 17 & 15 & 16 & 1,2 & 1,1 \\
\hline $\mathrm{Pb}$ & 28 & 30 & 23 & 0,9 & 0,8 \\
\hline
\end{tabular}

Táboa 1: Concentración de elementos maioritarios, minoritarios e traza do fragmento campaniforme, e relacións entre o contido nas caras (exterior e interior) respecto do da mostra total (E/T, I/T).

A comparación entre a composición elemental das caras en relación a da mostra total (táboa 1) indica unha alta homoxeneidade da peza analizada. Dos vintedous elementos analizados nas caras e na mostra total, tan só sete presentan anisotropía espacial (é dicir, diferencias de concentración no espesor da peza). O Si e o Y están lixeiramente empobrecidos na parte exterior (relacións E/T e I/T arredor de 0,65-0,78), e por tanto os minerais maoiritarios que os conteñen deben concentrarse no interior da sección da peza; o S está enriquecido no exterior da peza (rela- 
cións de 4,7-5,2) e por elo empobrecido no centro da cerámica; o Mn está enriquecido na cara exterior e lixeiramente empobrecido na cara interior; $\mathrm{Al}$ e $\mathrm{P}$ están empobrecidos na cara exterior e o Cr está lixeiramente empobrecido na cara interior da cerámica. Esta anisotropía composicional podería ser resultado de: 1) o acabado da peza, que daría lugar a unha distribución diferente dos minerais e por tanto dos seus elementos constitutivos (caso do $\mathrm{Si}, \mathrm{Y}, \mathrm{Al}$ ); 2) da queima diferencial da materia orgánica contida na pasta debido a maior temperatura acadada na sua cara externa (para o P, si fora de orixe orgánico); 3) ou dunha redistribución ligada as condiciones oxidantes/reductoras durante a cocción, ou as do ambiente xeqoquímico tralo enterramento (para elementos de forte compoñente redox, como o Mn e o $\mathrm{S}$; e probablemente tamén para o $\mathrm{Cr}$ ). Por outro lado, compre destacar de novo a alta homoxeneidade xeral da composición da peza, ó que contribúe sin dúbida o pequeno tamaño de grao dos minerais, que facilita unha mellor homoxeneización da pasta.

\section{COMPARACIÓN COA LITOLOXÍA DA ZONA}

O xacemento de Forno dos Mouros atópase na parroquia de Paradela, no Concello de Toques a unha altitude de $713 \mathrm{~m}$. Está situado sobre unha gran banda de rochas graníticas antehercínicas, concretamente ortoneises de grao groso e cores claras que dan lugar a bos afloramentos en bolos. Os ortostatos do propio dolmen están construidos nesta mesma rocha; cuia mineraloxía característica é cuarzo, plaxioclasa, feldespatos e micas, estando a plaxioclasa bastante alterada. En base á xeoquímica e a mineraloxía, a materia prima desta peza -arxila e desgrasantespuido provir de materiais de alteración destas mesmas rochas. Así o atestiguarían os contidos de $\mathrm{Zr}, \mathrm{Rb}, \mathrm{Y}, \mathrm{Ga}$ e $\mathrm{Pb}$, por exemplo, típicos de rochas ácidas; e os baixos contidos de elementos metálicos $(\mathrm{Zn} \mathrm{e} \mathrm{Cu}$ ), de $\mathrm{Ca}$ ou $\mathrm{Sr}$, que habitualmente están enriquecidos nas rochas básicas e ultrabásicas. O que resulta excepcinonal para o contexto litolóxico é o alto contido en ferro -unido á cor roxiza-, pero que é coherente coa presencia de hematita. Polo tanto é moi probable que sobre unha base de arxilas de orixe granítica se engadiran outros minerais alóctonos. -a non moita distancia do xacemento (menos de $1 \mathrm{~km}$ ) hay numerosos pequenos afloramentos de anfibolitas antehercínicas que dan lugar a solos alaranxados e vermellos característicos. Tamén existen, a distancias non maiores de $15 \mathrm{~km}$ (Igme, $\mathrm{n}^{\circ}$ 71, 1:50.000), formacións do Terciario con arxilas e arxilas areosas, algunhas con niveis de lignito e ricas en ferro, que na actualidade conforman cinco explotacións cerámicas para ladrillería. Ademáis a área onde se ubica o xacemento está rodeada polos comple- 
xos de Sobrado e Melide e da serie de Ordes, onde están presentes xistos e paraneises básicos e rochas metabásicas e peridotitas, rochas ferromagensianas que amplían o espectro mineralóxico dispoñible para obter as pastas e materiais desgrasantes. Unha análise de elementos traza máis específicos (como as terras raras) podería contribuir a precisar mellor a procedencia concreta dos materiais empregados na fabricación deste vaso campaniforme.

\section{SÍNTESE E VALORACIÓN}

A FABRICACIÓN: COMPOSICIÓN, PROCESADO DO MATERIAL E COCCIÓN

En resume, a partir do estudio arqueométrico podemos sinalar os seguintes aspectos: 1) a mineraloxía base da cerámica é moi sinxela, identificándose só tres tipos de minerais (cuarzo, hematita e haloisita); 2) a distribución do desgrasante é bastante homoxénea e aparece seleccionado no mineral (o cuarzo) e na granulometría (fina), aínda que está lixeiramente enriquecido no interior da cerámica en relación as caras externas; 3) dada a composición elemental parece posible que sobre unha pasta base de natureza granítica se engadiran mineráis procendentes de outras litoloxías; 4) a peza ten unha elevada homoxeneidade composicional en todo o seu espesor, agás para uns poucos elementos químicos; 5) non se aprecia fenómeno sandwich, a cor do corazón e dos exteriores en corte fresco é similar (roxiza). Todo isto indica unha coidada selección e preparación da materia prima, similar á realizada nas pezas campaniformes da área Ulla-Deza (xacementos de Zarra de Xoacín, Túmulo de A Romea e Devesa do Rei), sen embargo con adición de diferentes desgrasantes (Martínez, Lantes e Prieto 2008); e unha cocción oxidante progresiva e homoxénea, superior ós 500- $600{ }^{\circ} \mathrm{C}$.

\section{A FUNCIÓN}

As características da pasta son dureza e boa calidade, cunha arxila homoxénea e un desgrasante ben mezclado de granulometría fina $(0,1-0,3 \mathrm{~mm})$ e abundante. $\mathrm{O}$ alto contido en ferro, quizáis apreciado á hora de seleccionar a pasta pola coloración que lle aporta, é agora, co paso do tempo, quen lle proporciona unha fractura lixeiramente débil á cerámica por procesos de alteración e oxidación posteriores. O espesor da peza é inferior a $6 \mathrm{~mm}$, o que a fai fina e delicada.

A ausencia de acabado interno pode deberse a que se fora desprendendo e alterando a capa de arxila co tempo, un proceso de alteración quizáis axudado polo contido líquido que puido albergar no seu tempo de uso e que puido favorecer o desconchado interno que apreciamos hoxe. O desprendemento desta capa indica 
que o grosor debeu de ser superior en 1-3 mm, o que o faría máis resistente á hora de ter unha función de contención de productos.

Estes rasgos, ós que se suma o gran tamaño do vaso, permítennos valorar que éste albergara algún tipo de líquido, más concretamente bebida alcohólica como ofrenda ó defunto, coma se ven plantexando desde hai anos (por exemplo Sherratt 1991). Se ben non é probable que este fora pensado para o consumo directo senón para deixar colocado ó caron do corpo.

De feito, a introducción dunha gran cantidade de desgrasante, aínda que é pouco habitual en recipientes fabricados para conter líquidos, parece consciente e podería estar relacionada co feito de que ofrece unha mellor resistencia á temperatura, non tan só no uso senón no proceso de fabricación. Unha maior resistencia térmica asegura máis éxito na fase de cocción optimizando todo o traballo de modelado e decoración.

\section{A CIRCULACIÓN}

Os datos xeoquímico-mineralóxicos interpretados en base á litoloxía local indican que non hai motivos para pensar que o cacharro procede de fora xa que unha gran maioría de materiais orixinais da zona dan lugar a arxilas e desgrasantes das mesmas características que os utilizados como materia prima no fragmento campaniforme. Se ben, para poder afirmar con absoluta precisión a orixe local, incluso para concretar o material exacto de partida, faríase necesario outras análisis dos productos de alteración in situ das rochas da área (terras raras, composición isotópica).

Aínda que as análises petrográficas son insuficientes, apuntan a que, en Francia, os vasos campaniformes circulan pouco (Querre 1992) e en distancias máis modestas do que se supuña, sendo a materia prima obtida nun radio inferior a $10 \mathrm{~km}$ do entorno dos xacementos (Convertini e Querré 1998). De feito atestíguase a circulación duns poucos vasos (Querre 1992), pero elo non explica completamente a vasta distribución do campaniforme estándar. Este resultado é similar ó atopado para a cerámica campaniforme de outras zonas veciñas, como Portugal (Dias et alii 2005). A orixe local, deixa tamén unha certa impronta composicional nas pastas doutros xacementos galegos das zona do Ulla e o Deza. Así, A Romea e Zarra de Xoacín, que se asentan sobre materiais básicos, teñen cerámicas de composicións máis máficas, mentres que en Devesa do Rei, ubicado nun sector de rochas graníticas, as cerámicas son preferentemente de composición félsica (Martínez, Lantes e Prieto 2008).

Noutra orde de cousas, as investigacións de Price, Grupe e Schröter (1998), constataron, a partir da análise de isótopos de estroncio realizados sobre 69 mostras de dentaduras de individuos documentados en contextos funerarios de Baviera, un 
grado de mobilidade terrestre duns $200 \mathrm{~km}$ de distancia. Os exemplos que demostran a existencia de circulación terrestre e marítima en diferentes niveis das vida das comunidades campaniformes son innumerables en toda Europa.

A semellanza técnica da decoración do vaso de Forno dos Mouros con moitos vasos bretons é íntima, pero a súa orixe local é case indudable. Parece difícil pensar que esta decoración sexa unha orixinalidade do alfareiro que fabricou este vaso en particular, e máis, tendo en conta o contexto específico galego no que aparece e a frecuencia coa que se presenta noutras rexións fisterrás da costa atlántica. De feito, parece coherente pensar que se os vasos non circulan, entón, a clave está na transmisión das técnicas a longa distancia (Salanova 1997) que forma parte dunha rede complexa de circulación económica pero sobre todo social e cultural ó longo da costa atlántica, e o campaniforme de Forno dos Mouros podería ser un exemplo material de este proceso.

\section{AGRADECEMENTOS}

Este artículo foi realizado no marco do proxecto titulado "Aplicación de técnicas arqueométricas ao estudo da cerámica antiga de Galicia" (código: PGIDIT07PXIB236075PR) concedido pola Dirección Xeral de Investigación, Desenvolvimento e Innovación (I+C+I), Xunta de Galicia dentro del Programa de Promoción Xeral de Investigación do Plan Galego de Investigación, Desenvolvemento e Innovación Tecnolóxica (INCITE) de 2007 e tamén coa axuda dunha beca de investigación postdoctoral na Universidade de París X, entre 2006 e 2007 obtida por unha das firmantes, P. Prieto, que foi cofinanciada pola Consellería de Innovación e Industria da Xunta de Galicia e o Programa Operativo Integrado de Galicia (F.S.E.) das UE. Ademáis, agradecemos a Laure Salanova, pola súa boa acollida en París para estudiar o campaniforme bretón, a súa axuda para recoñecer a impresión de cuncha e polo seu apoio para que resultase máis fácilmente accesible o material estudiado dos distintos museos visitados. Asimesmo, a Anxo Rodríguez Paz a realización dos debuxos e reconstruccións en autocad.

\section{BIBLIOGRAFÍA}

ANDRÉS, A. M.; MENÉNDEZ, P. \& MUÑOZ, I. "Estudio arqueométrico de cerámicas prehistóricas gallegas”, El Cuaternario en España y Portugal. Instituto Tecnológico Geominero de España, Madrid 1993, 357-67. 
BARFIELD, L. H. "The cultural affinities of Bell Beaker in Italy and Sicily", Glockenbecher Symposion, Oberried 1974, 307-22.

CERQUEIRO LANDÍN, D. "As Gándaras de Budiño: Prehistoria e Historia”, en Fábregas Valcarce (ed.) Os primeiros poboadores de Galicia: O Paleolítico, Sada 1996, 47-73.

CLARKE, D. L. Beaker pottery of Great Britain and Ireland, Cambridge University Press, Cambridge 1970.

CONVERTINI, F. \& QUERRÉ, G. "Apports des études céramologiques en laboratoire à la connaissance du Campaniforme: résultats, bilan et perspectives", Bulletin das Société Préhistorique Française, 95 (3) (1998), 333-41.

CRIADO BOADO, F. (dir.), BONILLA RODRÍGUEZ, A., CERQUEIRO LANDÍN, D., DÍAZ VÁZQUEZ, M., GONZÁLEZ MÉNDEZ, M., INFANTE ROURA, F., MÉNDEZ FERNÁNDEZ, F., PENEDO ROMERO, R., RODRÍGUEZ PUENTES, E. \& VAQUERO LASTRES, J. Arqueología del Paisaje. El área del Bocelo-Furelos entre los tiempos paleolíticos y medievales. (Campañas de 1987, 1988 y 1989), Arqueoloxía/ Investigación 6, A Coruña 1991.

CRIADO BOADO, F. \& VAQUERO LASTRES, X. 1991. "El fenómeno megalítico y tumular: formas diversas de pasado monumental", en Criado Boado (dir.), A Coruña 1991, 129-46.

DIAS, M. I.; VALERA, A. C. \& PRUDENCIO, M. I. "Pottery production technology throught the third millennium BC on a local settlement network in Fornos de Algobres, central Portugal", en M. I. Prudêncio, M. I. Dias \& J. C. Waerenborgh (eds.) Proceedings of the 7th European Meeting on Ancient Ceramics- Understanding people through their pottery, Lisboa 2005, 41-8, Trabalhos de Arqueologia, 42.

EGUILETA FRANCO, J. M., FERNÁNDEZ IBÁÑEZ, C. \& SEARA CARBALlO, A. "Un campaniforme cordado procedente de A Limia (Ourense)", Brigantium, 8 (1993-4), 57-67.

GUITIÁN RIVERA, F. \& VÁZQUEZ VARELA, J. M. "Sobre la tecnología de la cerámica castreña: determinación de la temperatura de cocción”, Arqueologia, 4 (1981), 89-93.

HARRISON, R.J. The Bell Beaker cultures of Spain and Portugal, Peabody Museum of Archaeology and Ethnology, Cambridge-Massachusetts 1977.

IGME. Mapa Geológico. 1: 50000, nº 71 (6-6). Sobrado dos Monjes. Segunda serie. Primera edición.

JENSEN, J. A. “Bopladse Myrhøj. 3 hustomter med klokkebaegerkeramik”, Kulm 1972 (1973): 61-122.

JORGE, S. O. "An All-over Corded Bell Beaker in Northen Portugal. Castelo Velho de Freixo de Numâo (Vila Nova de Foz Côa). Some remark", Journal of Iberian Archaeology, 4 (2002), 107-29.

MARTÍNEZ CORTIZAS, A., LANTES SUÁREZ, Ó e PRIETO MARTÍNEZ, M. P. "Análisis Arqueométrico de la Cerámica prehistórica del Área Ulla-Deza”, en M. P. Prieto-Martínez, F. Criado-Boado e A. Rodríguez Costas (Coords.) Autopista al pasado. Arqueología y paisaje en la ACEGA, entre Santiago y el Alto de Santo Domingo, Santiago de Compostela 2008 (en prensa), Traballos de Arqueoloxía e Patrimonio, 37.

MÉNDEZ FERNÁNDEZ, F. "La domesticación del paisaje durante la Edad del Bronce gallego", Trabajos de Prehistoria, 51 (1) (1994), 77-94.

MÉNDEZ FERNÁNDEZ, F. "Definición y análisis de poblados de la Edad del Bronce en Galicia”, en R. Fábregas, (ed.). A Idade do Bronce en Galicia: novas perspectivas, Sada 1998, 153-89. 
PEÑA SANTOS, A. "Sondeo estratigráfico en el yacimiento de 'A Fontenla' Moaña)", Pontevedra Arqueológica, I (1985), 91-8.

PRICE, T. D., GRUPE, G. \& SCHRÖTER P. "Migration in the Bell Beaker period of central Europe", Antiquity, 72 (1998). 405-11.

PRIETO MARTÍNEZ, Ma . P. Aproximación al análisis formal de la cerámica de la Edad del Bronce en Galicia. Santiago de Compostela 1993, Traballo de Investigación do Tercer Ciclo inédito.

PRIETO MARTÍNEZ, M. P. Forma, Estilo y Contexto en la Cultura Material de la Edad del Bronce Gallega: Cerámica Campaniforme y Cerámica No Decorada. Universidad de Santiago (Edición en CD), Santiago de Compostela 1999a.

PRIETO MARTÍNEZ, M. P. "Caracterización del estilo cerámico de la Edad del Bronce en Galicia: cerámica campaniforme y cerámica no decorada”, Complutum, 10 (1999b), 71-90.

PRIETO MARTÍNEZ, M. P. "Unity and circulation. What underlies behind the homogeneity of Galician Bell Beaker style?", en L. Salanova e G. Querré (eds.) Mécanismes de circulation des vases campaniformes. Table ronde de Nanterre, Revue Archéologique de l'Ouest (2007, en prensa).

PRIETO MARTÍNEZ, M. P. "Bell-beaker communities in Thy. The first Bronze Age society in Denmark", Norwegian Archaeological Review (2008, en prensa).

PRIETO MARTÍNEZ, Mª P.; JUAN-TRESSERRAS, J. \& MATAMALA J. C. Ceramic Production in the North-Western Iberian Peninsula: Studying the functional features of pottery by analyzing organic material", en M. I. Prudêncio, M. I. Dias \& J. C. Waerenborgh (eds.) Proceedings of the 7th European Meeting on Ancient Ceramics- Understanding people through their pottery, Lisboa 2005, 193-199, Trabalhos de Arqueologia, 42.

QUERRÉ, G. "Les céramiques campaniformes du Sud-Finistère, nature et provenances; premiers résultats", Antiquités Nationales, 24 (1992), 26-33 e 47.

REY CASTIÑEIRA, P. \& SOTO ARIAS, P. "Estudio Preliminar del análisis físico-químico aplicado a la cerámica castreña: Vertiente atlántica gallega", Gallaecia, 21 (2002), 159-76.

RODRÍGUEZ CASAL, A. A. La necrópolis megalítica de Parxubeira, Monografías Urxentes do Museu 4, A Coruña 1989.

SALANOVA, L. "Le décor à la coquille dans le Campaniforme du Sud-Finistère", Revue Archéologique de l'Ouest, 9 (1992a), 79-81.

SALANOVA, L. "La céramique campaniforme du Sud-Finistère.", Antiquités Nationales, 24 (1992b), 9-24 e 34-46.

SALANOVA, L. "Le campaniforme en France et dans les îles Anglo-Normandes: Caractérisation des productions céramiques", Bulletin das Société Préhistorique Française, 94 (2) (1997), 259-64.

SALANOVA, L. La question du campaniforme en France et dans les Iles anglonormandes: productions, chronologie et rôles d'un standard céramique. Coédition Société Préhistorique Française et Comité des Travaux Historiques et Scientifiques, Paris 2000.

SHERRATT, A. "Sacred and profane substances: the ritual use of narcotics in Later Neolithic Europe", Proceedings of a Conference on Archaeology. Ritual and Religion, Oxford 1991, 50-64, Oxford University Commitee for Archaeology Monographs, 32. 
SUÁREZ OTERO, J. \& LESTÓN GÓMEZ, M. "Un vaso con decoración cordada en Galicia y el problema de los orígenes de la cerámica campaniforme en el occidente ibérico", Madrider Mitteilungen, 46 (2005), 1- 21.

TABOADA, M. T.; CARREÑO GASCÓN, M. C. \& GUITIÁN RIVERA, F. "Mineralogía y condiciones de cocción de la cerámica del Castro de Saceda (Orense)", en J. F. Jordá (ed.) Geoarqueología. Actas de la $2^{a}$ Reunión Nacional de Geoarqueología, Madrid 1992, Madrid 1994, 391-97.

TABOADA, T; MARTINEZ CORTIZAS, A; GARCÍA, C. \&. EDUARDO GARCÍA-RODEJA. "Particle-size fractionation of titanium and zirconium during weathering and pedogenesis of granitic rocks in NW Spain”, Geoderma, 131 (2006), 218-236. 